\title{
Multiplex Versus Multiple Taxonomy of Paraphilia: Case Example
}

\author{
Gregory K. Lehne ${ }^{1,3}$ and John Money ${ }^{1,2}$
}

Several different paraphilias are presently diagnosed in some individuals whereas a more parsimonious taxonomy would be that of one multiplex paraphilia. A multiplex paraphilia may be expressed by variations of content at different times in an individual's life or in different situations. The present case example shows the unfolding of a multiplex paraphilia over a lifetime. At age 7 the subject was dressed in public as a girl wearing a diaper as a humiliation for bed-wetting. This experience had 3 paraphilic components that were separately manifested at different times in his life: fetishistic transvestism, pedophilic incest, and infantilism. A multiplex paraphilia taxonomy may lead to improved identification of etiology, prognosis, and treatment of paraphilia.

KEY WORDS: paraphilia; transvestism; infantilism; incest.

\section{INTRODUCTION}

Paraphilias are sexological syndromes that are classified according to the content of the sexual fantasies or behavior. There are over 40 named paraphilias (Money, 1986, 1999). A subset of the more common paraphilias is listed with specific diagnostic numbers in the Diagnostic and Statistical Manual of Mental Disorders (DSM-IV; American Psychiatric Association[APA], 1994): exhibitionism, fetishism, frotteurism, pedophilia, sexual masochism, sexual sadism, transvestic fetishism, and voyeurism. The residual DSM-IV category of Paraphilia Not

\footnotetext{
${ }^{1}$ Department of Psychiatry and Behavioral Sciences, The Johns Hopkins University School of Medicine, Baltimore, Maryland.

${ }^{2}$ Department of Pediatrics, The Johns Hopkins University School of Medicine and Hospital, Baltimore, Maryland.

${ }^{3}$ To whom correspondence should be addressed at Human Ecology Center, 4419 Falls Road, Baltimore, Maryland 21211; e-mail: gregory.lehne@ verizon.net.
} 
Otherwise Specified lists additional examples: telephone scatologia, necrophilia, partialism, zoophilia, coprophilia, klismaphilia, and urophilia. There is presently no standard classification system that lists or categorizes all of the possible paraphilias according to the content of erotic behavior in imagery or action. The scope of such a classification system would depend upon how the paraphilias are either subdivided or combined into named categories.

$D S M-I V$ notes that paraphilias can be obligatory for sexual arousal or may occur only episodically. DSM-IV also states "not uncommonly, individuals have more than one paraphilia ... The individual paraphilias can be distinguished based on differences in the characteristic paraphilic focus. However, if the individual's sexual preferences meet criteria for more than one paraphilia, all can be diagnosed" (APA, 1994, p. 523). DSM-IV diagnostic criteria are vague but in general require the presence "over a period of at least 6 months, recurrent, intense sexually arousing fantasies, sexual urges, or behaviors involving" the focal content of the named paraphilia, and which cause clinically significant distress or impairment.

$D S M-I V$ encourages the idea than an individual may be diagnosed as having multiple paraphilias, which is consistent with behavioral researchers who report high frequencies of multiple paraphilic diagnoses (e.g., Abel et al., 1987; Abel, et al., 1988). The taxonomic alternative is to diagnose a single paraphilia where the components expressed through fantasy or behaviors are interconnected around a prodromal paraphilic fixation. For example, DSM-IV differentiates sexual masochism and sexual sadism, although in individual histories both these diagnoses may coexist as sadomasochism.

A paraphilic history often contains specific early experiences, typically before the age of 8-10, which embody the paraphilic content (Herdt \& McClintock, 2000; Keyes \& Money, 1993; Money, 1993, 1997, 1999; Money \& Lamacz, 1989; Money, Wainwright, \& Hingsburger, 1991). Throughout the course of the individual's life, different aspects of the paraphilia may become focused in fantasy and/or behavior. Such paraphilias are herein conceptualized as multiplex. A multiplex paraphilia is a paraphilia having many parts or elements, each interconnected around a primary fixation. Multiplex paraphilias can be named by their most inclusive manifestation (Money, 1999).

Some multiplex paraphilias are idiosyncratic and do not fit into discrete DSM$I V$ diagnostic categories. The specificity of a multiplex paraphilia may provide information about the contribution of early experience to the development of the paraphilia. In these cases, the fixated experience may be like the elephant being examined by the blind men. Each paraphilic expression may represent one perspective of the elephant. All of the expressions taken together (perhaps over the course of a life history) give a three-dimensional perspective, which depicts in the mind/brain the fixated experience as represented in the multiplex paraphilia. 


\section{CASE EXAMPLE}

The present case example illustrates the sexological history of one man with a multiplex paraphilia. He has given permission for the use of his case example and quotations from his record for educational purposes, and identifying information has been altered to protect his privacy. The man initially presented with symptoms of transvestic fetishism, which then became the primary paraphilic diagnosis. He had an adolescent history of gay bashing behavior that might have embodied aspects of sadism. Some years later the man sexually molested his 6-year-old son, suggesting an additional diagnosis of pedophilia. He again molested his son as an adolescent, which is suggestive of ephebophilia. For the last 20 years he has considered himself an "adult baby" or practitioner of infantilism (autonepiophilia, a fixation on wearing diapers and being treated like an infant), and has not crossdressed in adult garments. In DSM-IV, his diagnosis would be Paraphilia Not Otherwise Specified. The case history has been published as an example of paraphilia treated with Depo-Provera (Lehne \& Money, 2000; Money, 1970; Money et al., 1975; Money \& Bennett, 1981). The life history shows early childhood experiences dating from age 6 which correspond to the prodromal fixation of a multiplex paraphilia that was behaviorally manifested in different ways at different times in life.

At age 25, this man contacted one of the authors seeking information about transvestism. He was married, and had some contact with the heterosexual transvestite community. He remained in episodic contact for the next 40 years, participating in 55 interviews that were audiotaped and transcribed. His wife and son were also interviewed. He wrote brief autobiographies in 1964-66, 1984, and 1989. The quotations in this present report are taken with his permission from these interviews and writings.

\section{Contributing Experience: Cross-Dressed for Punishment}

Early in first grade, when he was 6, a nun punished him for tardiness and disruptive behavior by making him wear a girl's dress. He reported his memory of that experience: "The first that I can recollect of ever being dressed in female attire was the age of six at St. Pius School. In those days boys wore very short pants, white shirts and ties; girls wore neat pretty dresses. I remained in my shorts and T-shirt, and the dress was put over top that. For the day I sat on the girl's side of the classroom, took recess with them as well as lunch. At recess time the children in the class stood around, crossing their fingers. Sissy, sissy, shame, and millions of other things were said. I stood there and cried. I was ashamed, I was hurt and wanted to get out of those clothes and I knew I didn't dare tear them off. I didn't have any sexual thrill at all. I cried a lot that day, and later I fought a lot with those who taunted me." 


\section{Critical Experience: Cross-Dressed as Punishment for Bed-Wetting}

His mother used a similar technique to try to change his persistent bed-wetting when he was 7. She had tried other forms of punishment and humiliation in an attempt to break him of this "bad habit," and copied from the nuns the punishment of dressing him in girl's clothes. She paraded him around the streets of the housing project where he lived wearing a girl's blouse and skirt over diapers, with a handlettered sign announcing that he was a sissy baby because he wet the bed. He reported that the taunting and jeering of some children who saw him brought tears to his eyes, which he held back as best he could until his mother brought him back home.

This incident was reported early in his history of contact with the author. After the initial report of this incident, it was subsequently reported without any reference to diapers or being a baby. For the next 20 years there were no hints of diapers or baby-like behavior in fantasies or behavior.

\section{Emergence of Transvestism}

There were no further punishments by cross-dressing, but the next episode of wearing girl's clothing that he reported resulted in his being laughed at. His mother used him as a dressmaker's dummy. "I think the real turning point for my transvestism came when I was about nine or ten years old. My mother was making a skating skirt for a cousin of mine. She's about the same age as I am, and she wanted to have me model it so she could pin it up and finish the job. I protested but it didn't do any good and then I modeled the skirt while she hemmed it. One of the neighbors came in and she wouldn't let me take it off. She just kept on working and I got a few laughs." He said that he was not embarrassed by this experience, but thought that he secretly enjoyed it.

The sequel to this experience surprised him. "I found myself digging into that skirt after it had been put away and wearing it around the house when no one was there. And from then on I had this impulse to wear female attire. I wore my mother's frequently as it was the only clothing available. The only thing I know is that the skirt felt appealing to me and I went back after it. I don't know what made me do it or what caused me to do it, but I wore it frequently until it was given to my cousin. I felt comfortable and I felt right at ease. I would borrow a pair of my mother's panties each time when I would wear the skirt and I enjoyed the feel of that, the soft undergarments against my skin with the skirt flouncing around my legs. The undergarments would have to be female. I like pretty laces and things like that. And, even at nine I had erections that would last just about the entire time that I was dressed. I'd rub myself or if I'd look in the mirror, I would again have an erection. I would just rub myself on the clothing, I'd feel the soft material against my penis." 
The cross-dressing became the focus of masturbation in his teenage years. "The desire was so strong I couldn't resist to put the clothing on. The feeling of the soft undergarments against my body would cause an erection, and eventually I would have to masturbate for relief. After masturbating I felt somewhat relieved and replaced the garments. I would remain motionless after my climax drinking in the beautiful feeling that surrounded me. Then each time after such an episode I would look at myself, and the pangs of guilt would creep upon me and often I would cry, swearing each time would be the last. This happened quite often and the anxieties caused by my desire for female clothing created mixed feelings of guilt and pleasure, both beyond description."

\section{Early Adolescent Sexual Experience With a Man}

He had a homosexual experience with an older male when he was about age 12. He was walking through the neighborhood when a man in his 40 s offered to pay him for "some work." The man took him to a wooded area, performed fellatio on him and also asked him to perform fellatio. He was pleased with the quarter the man paid him, which seemed like a lot of money at the time, and was not upset by his experience.

\section{Behavioral Episodes of Adolescent Homosexual Hustling}

His next homosexual experiences involved hustling older homosexual men for money when he was age 14-17. He had mixed feelings about these experiences. "You went down there because of the money but sooner or later you started to enjoy it. And you lied to yourself. You weren't enjoying this, you told yourself, it was strictly done for the money. I didn't believe I had homosexual tendencies because of the way it revolted me after it was over. Of course I enjoyed the blow job itself and the emission, and then afterwards it seemed, I don't know how to describe it, this gloomy feeling came over me and I hated myself and I hated this character that had just finished blowing me. And the money, the easy money always did elate me. But even that wouldn't make the difference. I'd take the money and I'd still feel disgusted."

With a group of neighborhood toughs, he engaged in episodic robbery and sadistic gay bashing, and then went home and cross-dressed. He reported that the cross-dressing was sexually exciting and also calming.

\section{Transvestism and Marriage}

He was 21 when he fell in love and married. He had a strong sexual attraction to his wife. He hoped that settling down in marriage with a regular sexual relationship 
would allow him to put cross-dressing behind him. He told his wife about his transvestism, or as he then labeled it, his "sexual fetish" for women's clothing.

He did not engage in cross-dressing at the start of the marriage. His sexual relationship with his wife was reportedly exciting and frequent. But later in the 1st year of the marriage, the urges to dress in women's clothes returned with an intensity and urgency that he had not experienced before. He started secretly dressing in his wife's clothes. Gradually he acquired a wardrobe for himself. He tried to recruit his wife's assistance and support, being very insistent in his demands upon her. He wanted her to go with him to buy clothes, make-up, and fashion accessories. His dressing progressed to wanting to wear complete outfits and hang around the house with his wife as if they were girlfriends.

He tried to incorporate cross-dressing into his marital sexual relationship. At first, he wanted to have sex with his wife after episodes of cross-dressing. Then, he wanted to be cross-dressed during sexual relations. His wife, attracted to his masculine good looks, attempted to tolerate this but soon found that it was a sexual turn-off for her. She refused to engage in any sexual activity if he had been crossdressing beforehand. However, she did tolerate his cross-dressing occasionally for transvestite social club activities, and when she was not around or when he was away on business trips. For his wife, cross-dressing was always a problem in the marriage. He had periods of time when he did not cross-dress, and other times when he did it secretly so that his wife did not know he was still engaging in the behavior. While engaging in cross-dressing, he could masturbate to orgasm two to eight times a day.

\section{Behavioral Episode: Cross-Dressing and Incest With Son}

When he was 30, he began to play what he called "TV games" with his 6year-old son. He encouraged and bribed the boy to dress in girls' dresses, which he provided. Initially, the boy did not seem to object to playing these games with his father. However, the games progressed with the father masturbating or performing fellatio on his son, which the son did not like. The son told his mother the secret about the TV games and the sexual activity. His mother immediately sought treatment for the whole family (Money, 1970). The father's treatment included use of the antiandrogenic hormone, Depo-Provera (medroxyprogesterone acetate; Lehne \& Money, 2000; Money et al., 1975).

The physical examination of the father showed no abnormalities, with testosterone level in the typical range $(550 \mathrm{mg}$ per $100 \mathrm{ml})$ and weight (140 pounds) relatively low for height. The dosage of Depo-Provera used for this first case of treatment was lower than current practices. After an initial higher dose it was maintained at $150 \mathrm{mg}$ every 2 weeks for 20 months of the 24 months of treatment. Testosterone level was reduced to a low level of $50 \mathrm{mg}$ per $100 \mathrm{ml}$, and would rise by the end of each 2 -week period allowing him to engage in marital sexual 
relations. During treatment, he reported a total cessation of fantasies and urges to engage in cross-dressing or any type of sexual contact with children. The main side effects he experienced were weight gain (to 185 pounds), increased tiredness, and increased sleep. He was not treated with any other medications.

Concurrently with Depo-Provera treatment, there was a $2 \frac{1}{2}$ year remission from cross-dressing as well as a cessation of sexual activity with his son. There were some brief relapses into cross-dressing during the ensuing 3 years between ages 33 and 36. In a series of photographs taken when he was 36 , he posed in a maternity dress, looking pregnant.

\section{Behavioral Episode: Fondling Young Adolescent Son}

When he was 37 , he went into his 13 -year-old son's room one night, and fondled the boy's penis. This apparently took place on only one occasion, while the son feigned sleep. The son reported this to his mother the next day, which led to a resumption of individual and family counseling. Depo-Provera treatment was resumed. For the next 6 years, he reported little sexual interest and no relapses into cross-dressing or sexual interest in his son or other children.

\section{Heterosexuality and Homosexuality}

As a young adolescent, he engaged in some group masturbation ("circle jerk") with male peers. His fantasies at the time were of heterosexual engagements. There were no overt homosexual activities or direct sexual contacts with each other among the participants.

While still a teenager he began dating girls and engaged in sexual relations with available partners. During his enlistment in the military, he had casual sexual relations with some of the women he met overseas, including some prostitutes. On at least one occasion, he had fallen in love with a particular woman but was not in a situation to develop an ongoing relationship.

After he met his wife, he did not engage in sexual relations with any other woman, with only one exception when he and his wife engaged in partner swapping with another couple for one evening.

He engaged in sexual relations with several men during his mid-20s. These relations occurred in connection with fantasies of himself as a woman having sexual relations with a man. He would go to a gay bar dressed as a woman in the hopes of meeting a male partner. Gay men were typically not interested in having sex with him while he was dressed as a female. He also would go out dressed as a male wearing female undergarments in order to meet men. He never considered himself gay or bisexual. He never sought to have sexual relations in a man-to-man way, thinking of himself as a man having sex with another man who treated him 
as a man. He never had fantasies of himself as a male having sexual relations with another male, nor did he ever fall in love with a male.

\section{Infantilism}

At age 45 he reported a sudden recurrence of paraphilic preoccupation. He did not engage in cross-dressing, but he had become involved in sexual fantasies and more frequent and adventuresome sexual relations with his wife. The main fantasy that was emerging was being an "adult baby." He described the main fantasy and associated activity: I enjoy "living as a baby whenever I have an opportunity. I love to lie in a diaper, powder myself and pin myself in tightly. I then slip on my rubber pants and prepare for bed." The experience of wearing and wetting in a diaper is the focus of this fantasy and behavior. He would use a nursing bottle to drink infant formula, and then wet in his diapers, change the diapers and later fall asleep. He engages in this activity about once or twice a week, sleeping in a baby bedroom apart from his wife on these nights. He described the experience as sexual, with a feeling of tremendous calm and satisfaction during these activities, but no genital arousal or ejaculation. He read and wrote fantasy stories about infantilism, in the course of which he would become aroused and masturbate. This practice of infantilism has continued as his paraphilic activity for 20 years.

\section{DISCUSSION}

In terms of taxonomic classification, it can be argued that this is a case of a man with multiple distinct paraphilic disorders that change over time or that it is a case of one multiplex paraphilia that is expressed by different symptoms during different times in the life history. The subject of this case study would clearly meet DSM-IV diagnostic criteria for Transvestic Fetishism (302.3) from age 9 to 37, Pedophilia (male, limited to incest; 302.2) at around age 30 only, and Infantilism (Paraphilia Not Otherwise Specified; 302.9) from age 45 to 65 . Based upon episodes of behavior, his beating up of gay men in connection with hustling as an adolescent might be considered evidence of sadism, and his sexual fondling of his teenage son suggested possible ephebophilia. Although the transvestism and infantilism appeared stable, with each lasting as a primary sexual interest for more than 20 years, there was a dramatic shift from one paraphilic focus (transvestism) to the other (infantilism) when he was in his early $40 \mathrm{~s}$.

This case illustrates some of the taxonomic problems that O'Donohue and his associates have discussed related to DSM-IV diagnosis of pedophilia (O'Donohue, Regev, \& Hagstrom, 2000). The case violates temporal consistency of diagnosis, in that the subject would meet diagnostic criteria for different paraphilias at different times, even though there apparently was no other change in the individual. There 
would be diminished inte-rater consistency and reliability for DSM-IV diagnoses made at different times in this man's history, or even at the present time with the life-historical information presented in this paper. The consistency and reliability problems arise when diagnosis is based upon the content of behavioral symptoms (i.e., cross-dressing; sex with a boy; wearing diapers) rather than the underlying syndrome, which we propose calling a multiplex paraphilia.

This case is not unusual in its presentation of multiple paraphilic symptoms. Several researchers reported that a majority of sex offenders could be diagnosed with multiple parpahilias (e.g., Abel et al., 1988; Kafka \& Prentky,1994). One study of adolescents who sexually molested children found that $95 \%$ had two or more paraphilias (Galli et al., 1999), while another study of adult pedophilic offenders found 53\% met criteria for an additional paraphilic diagnosis (Raymond, et al., 1999). At issue here is whether there are actually high rates of comorbidity of different paraphilias, or whether the present DSM-IV diagnostic system results in multiple diagnoses based upon different symptoms of a unitary (or multiplex) underlying disorder.

Men with paraphilia also had high rates of other comorbid psychiatric disorders in a number of research studies (Kafka \& Prentky, 1994, 1998; McElroy et al., 1999; Raymond et al., 1999). Childhood attention-deficit/hyperactivity disorders are more frequent in paraphilic populations, which may suggest that this disorder may be a risk factor for the development of paraphilia (Galli et al., 1999; Kafka $\&$ Prentky, 1998). Mood disorders are also prevalent among men with paraphilias. McElroy et al. (1999) found that paraphilic sex offenders had significantly higher rates of mood disorders (both depression and anxiety) than nonparaphilic sex offenders. Kafka and Prentky $(1994,1998)$ found high rates of concurrent mood disorders in men with paraphilias, but not significantly higher than in men with nonparaphilic sexual impulsivity behavior problems. Alcoholism and substance abuse disorders also have high rates of comorbidity with some paraphilic diagnoses (e.g., sexual sadism) but not others (e.g., pedophilia, fetishistic transvestism; Allnutt, et al., 1996). Obsessive compulsive disorders (OCD) have not been found to have a strong comorbid association with paraphilia, although Bradford (1999) has argued that perhaps some paraphilias could be considered part of the OCD spectrum because they seem to respond to treatment with SSRI medications.

The issue of comorbid psychiatric disorders is important, because it may help explain different responses to treatment of men with paraphilia. Antiandrogen treatment, combined with counseling, as in the present case example, is one helpful approach for the management of paraphilias where the individual experiences difficulty in controlling behavior because of the strength of the sexual urges (Lehne, Thomas, \& Berlin, 2000; Prentky, 1997; Rosler \& Witztum, 2000; Thibaut, Cordier, \& Kuhn, 1996). But paraphilias may be expressed in other situations where strong sexual urges are less of a determining factor. For example, paraphilias may be more likely to be expressed in behavior during periods of depression or anxiety. In these 
situations, treatment with SSRI medications may reduce the behavioral symptom expression even though it may not directly medicate the paraphilia (Balon, 1998). Similarly, alcohol and substance abuse are thought to be risk factors for acting out for some men with paraphilia. Twelve-step programs, which are frequently used to help people control alcohol or substance use, are also sometimes used as part of treatment of men with parpahilia. But the rates of comorbidity and the usefulness of 12 step programs in treatment do not necessarily imply that paraphilias are part of a spectrum of addiction disorders. Rather, comorbid conditions may need to be treated as a part of relapse prevention in men with paraphilia. Inadequate treatment of comorbid psychiatric disorders may contribute to sexual relapse (Raymond et al., 1999).

Diagnosis of a multiplex paraphilia is more parsimonious than the multiplication of separate paraphilia diagnoses. The prodromal fixation of the multiplex paraphilia in the case example is contained in the experience he had when he was 7-years old and was cross-dressed wearing diapers as a punishment by humiliation for wetting his bed. This first manifestation contains the three interconnected paraphilic fixations of being cross-dressed, cross-dressing a 6-year-old son, and wearing diapers. We propose that behaviors expressing these fixations are best classified as symptoms of one multiplex paraphilia manifested at different times in the life history.

Conceptualizing the present case as one of multiplex paraphilia has several implications for practice. The case history shows that the underlying condition of paraphilia has existed over the course of a life history despite changes in its manifest symptoms. If viewed in cross-section only, the symptoms would suggest that this man suffered from three or more separate and distinct paraphilic disorders. This could lead to the implication that one paraphilic disorder was cured, or at least went into remission, and then a new paraphilic disorder emerged. If treatment was specifically tailored to the content of the paraphilia, then treatment designed for cross-dressing might not be helpful in preventing pedophilic activity. Treatment of the pedophilia might not be relevant to preventing either the reoccurrence of cross-dressing or the subsequent expression of infantilism. Risk factors for relapse associated with one paraphilic content may not be relevant to avoiding another paraphilic content. Identifying the core content of the multiplex paraphilia, when possible, would suggest the possible risk situations or changes in manifestation in the future.

The present case is typical of the experiences of a number of men with multiplex paraphilias who were able to describe early fixated experiences that share common content with the paraphilia (Keyes \& Money, 1993; Money 1987, 1999; Money \& Lamacz, 1989; Money, Wainwright, \& Hingsburger, 1991). These early experiences were dated by Herdt and McClintock (2000) as occurring during the period of "adrenal puberty," about age 5-10, which has been hypothesized as a time when subjective sexual experiences may become stable and memorable. 
The experience of being cross-dressed, diapered, and infantilized when he was a 7-year-old boy as a punishment for bed-wetting was not on the surface a sexual experience. But it seems to have been encoded in the brain in a sexual way. The multiplex paraphilia then encapsulated the various aspects of that experience. This would be one parsimonious explanation of this man's paraphilic history. However, this experiential hypothesis does not address the underlying biological or brain physiological conditions that led the original experience to be sexually fixated or expressed as a paraphilia.

Multiple and multiplex paraphilias refer to the same phenomena in different conceptual ways. In many cases it is not possible to identify a multiplex paraphilia from recorded data if they are cross-sectional only, and not longitudinal. In moving from paraphilic symptoms to paraphilic etiology, the concept of multiplex paraphilia is indispensable.

\section{ACKNOWLEDGMENTS}

The research and writing of this paper was supported by NICHD Grant \#R25 HD00325-41.

\section{REFERENCES}

Abel, G. G., Becker, J. V., Cunningham-Rathner, J., Mittleman, M. S., \& Rouleau, J. L. (1988). Multiple paraphilic diagnoses among sex offenders. Bulletin of the American Academy of Psychiatry and the Law, 16, 153-168.

Abel, G. G., Becker, J. V., Mittelman, M. S., Cunningham-Rathner, J., Rouleau, J. L., \& Murphy, W. D. (1987). Self-reported sex crimes of nonincarcerated paraphiliacs. Journal of Interpersonal Violence, 2, 3-25.

Allnutt, S. S., Bradford, J. M., Greenberg, D. M., \& Curry, S. (1996). Co-morbidity of alcoholism and the parpahilias. Journal of Forensic Science, 41(2), 234-239.

American Psychiatric Association. (1994). Diagnostic and statistical manual of mental disorders (4th ed.). Washington, DC: Author.

Balon, R. (1998). Pharmacological treatment of paraphilias with a focus on antidepressants. Journal of Sex and Marital Therapy, 24, 241-254.

Bradford, J. M. W. (1999). The paraphilias, obsessive compulsive spectrum disorder, and the treatment of sexually deviant behaviour. Psychiatric Quarterly, 70(3), 209-219.

Galli, V., McElroy, S. L., Soutullo, C. A., Kizer, D., Raute, N., Keck, P. E., Jr., et al. (1999). The psychiatric diagnoses of twenty-two adolescents who have sexually molested other children. Comprehensive Psychiatry, 40(2), 85-88.

Herdt, G., \& McClintock, M. (2000). The magical age of 10. Archives of Sexual Behavior, 29, 587-606.

Kafka, M. P., \& Prentky, R. A. (1994). Preliminary observations of DSM-III-R axis I comorbidity in men with paraphilia and paraphilia-related disorders.Journal of Clinical Psychiatry, 55(11), 481-487.

Kafka, M. P., \& Prentky, R. A. (1998). Attention-deficit/hyperactivity disorder in males with paraphilias and paraphilia-related disorders: A comorbidity study. Journal of Clinical Psychiatry, 59(7), 388-396.

Keyes, R. W., \& Money, J. (1993). The armed robbery orgasm: A lovemap autobiography of masochism. Amherst, NY: Prometheus Books. 
Lehne, G., \& Money, J. (2000). The first case of paraphilia treated with Depo-Provera: Forty-year outcome. Journal of Sex Education and Therapy, 25(4), 213-220.

Lehne, G., Thomas, K., \& Berlin, F. (2000). The treatment of sexual paraphilias: A review of the 1999-2000 literature. Current Opinion in Psychiatry, 13, 569-573.

McElroy, S. L., Soutullo, C. A., Taylor, P., Jr., Nelson, E. B., Beckman, D. A., Brusman, L. A. et al. (1999). Psychiatric features of 36 men convicted of sexual offenses. Journal of Clinical Psychiatry, 60(6), 414-420.

Money, J. (1970). Use of an androgen-depleting hormone in the treatment of male sex offenders. Journal of Sex Research, 6, 165-172.

Money, J. (1986). Lovemaps. Buffalo, NY: Prometheus Books.

Money, J. (1987). Masochism: On the childhood origin of paraphilia, opponent-process theory, and antiandrogen therapy. Journal of Sex Research, 23(2), 273-275.

Money, J. (1993). The Adam principle, genes, genitals, hormones, \& gender: Selected readings in sexology. (pp. 302-304) Buffalo, NY: Prometheus Brooks.

Money, J. (1997). Principles of developmental sexology. New York: Continuum.

Money, J. (1999). The lovemap guidebook: A definitive statement. New York: Continuum.

Money, J., \& Bennett, R. (1981). Postadolescent paraphilic sex offenders: Antiandrogenic and counseling therapy follow-up. International Journal of Mental Health, 10, 122-133.

Money, J., \& Lamacz, M. (1989). Vandalized lovemaps. Buffalo, NY: Prometheus Brooks.

Money, J., Wainwright, G., \& Hingsburger, D. (1991). The breathless orgasm: A lovemap biography of asphyxiophilia. Buffalo, NY: Prometheus Books.

Money, J., Wiedeking, C., Walker, P., Migeon, C., Meyer, W., \& Borgaonkar, D. (1975). 47,XYY and 46,XY males with antisocial and/or sex-offending behavior: Antiandrogen therapy plus counseling. Psychoneuroendocrinology, 1, 165-178.

O'Donohue, W., Regev, L. G., \& Hagstrom, A. (2000). Problems with the DSM-IV diagnosis of pedophilia. Sexual Abuse: A Journal of Research and Treatment, 12, 95-105.

Prentky, R. A. (1997). Arousal reduction in sexual offenders: A review of antiandrogen interventions. Sexual Abuse, 9(4), 335-347.

Raymond, N. C., Coleman, E., Ohlerking, F., Christenson, G. A., \& Miner, M. (1999). Psychiatric comorbidity in pedophilic sex offenders. American Journal of Psychiatry, 156(5), 786-788.

Rosler, A., \& Witztum, E. (2000). Pharmacotherapy of paraphilias in the next millennium. Behavioral Sciences and the Law, 18, 43-56.

Thibaut, F., Cordier, B., \& Kuhn, J.-M. (1996). Gonadotrophin hormone releasing hormone agonist in cases of severe paraphilia: A lifetime treatment? Psychoneuroendocrinology, 21(4), 411-419. 